\title{
A pseudo-mesothelioma pleural revelant an carcinoma urothelial metastatic: about a case and review of the literature
}

\begin{abstract}
The authors illustrate through an observation of an aggressive and exceptional pleural evolution metastatic of a carcinoma urothelial of the upper urinary tract at the origin of an atypical radiological aspect and rarely described of pseudo-mesothelioma. In our case, the instillation with the BCG Pasteur by the percutaneous nephrostomy and the pleur X with the profit of a heavy chemotherapy enabled us to in fact circumvent the evolution towards the acute complications related to this pathology, the malignant pleuresis.
\end{abstract}

Keywords: BCG, chemotherapy, differential diagnosis, mesothelioma, radiotherapy, surgery, urothelial carcinoma
Volume 4 Issue 3 - 2017

\author{
Razafimanjato NNM,' Ravoatrarilandy M,' \\ Ralijaona HS,' Rakototiana AF,' Rakotovao HJL' \\ 'Department of Surgery \& Division of Thoracic Surgery, University \\ Hospital of Ampefiloha, Madagascar \\ ${ }^{2}$ Department of Surgery \& Division of Urology, University Hospital \\ of Ampefiloha, Madagascar
}

Correspondence: Razafimanjato Narindra Njarasoa Mihaja, Department of Surgery \& Division of Thoracic Surgery, University Hospital of Ampefiloha, Madagascar, Email razafesteban@yahoo.fr

Received: February 09, 2017| Published: June 21, 2017

\section{Introduction}

Urothelial carcinomas occur in over $90 \%$ in the bladder, but can also affect the pan (about 5\% of all kidney tumors), ureter and urethra. ${ }^{1}$ They give exceptionally pleural metastasis since in more than $75 \%$, it is secondary to primary malignancies of pulmonary origin, gynecological diseases and lymphoma. ${ }^{2}$ The authors describe here the first Malagasy case of urothelial carcinoma of the upper urinary tract radiological discovery late in pleural metastatic and discuss differential diagnoses of the image and the evolution of this tumor treated with topical agent adjuvant through review of recent literature.

\section{Observation}

Mr RAV. 53 years old, no smoking was hospitalized for progressive worsening of dyspnea lasting for 6 months, accompanied by chest pain basi-left. In the interview we noted a notion regularly taking a decoction of clinical médicinales. L'examen virtues plants entering found an alteration of the general status ( $\mathrm{PS}=3$ according to WHO), a left pulmonary syndrome without condensation fever. Radiography of thorax face showed pleural thickening picture left scalloped. Chest CT (Figure 1) confirmed the pleural lesions secondary look and abdominopelvic CT scan for staging (Figure 2) found a retroperitoneal mass compatible of renal tumor primitive right. Biologically, there was a LDH assay was raised to $1423 \mathrm{IU} / \mathrm{ml}$ (5 times normal). Histological examination of a biopsy transthoracic puncture confirmed the location of a secondary urothelial carcinoma at the pleura (pT4N2M1) (Figure 3). Our patient had received a course of BCG instillation Pasteur by percutaneous nephrostomy and the tear- $\mathrm{X}$ (thoracic drainage system) and died after three months of decline following the natural evolution of the tumor.

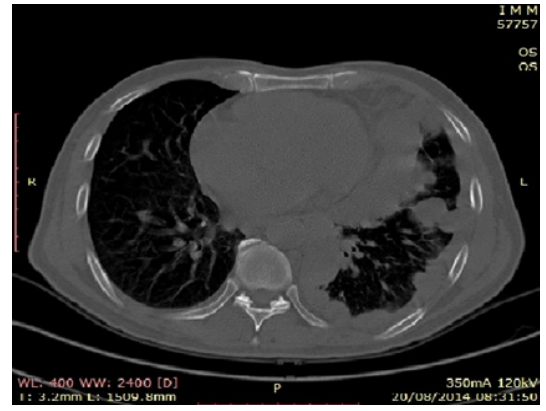

Figure I Chest CT scan showing regular pleural thickening withscalloped aspect of pleura revealing pleural malignant mesothelioma.

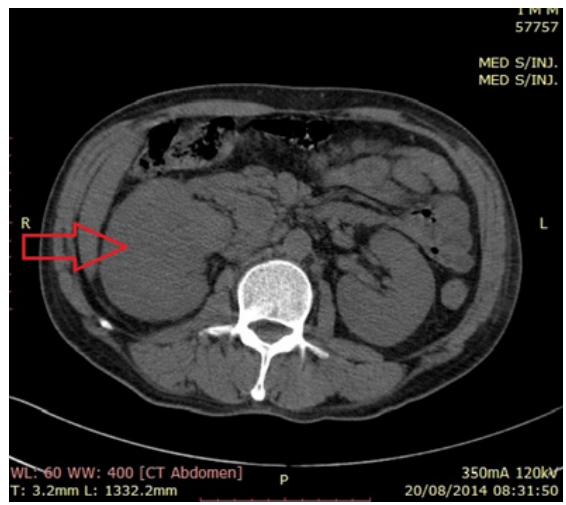

Figure 2 Abdominal CT scan showing UTUC infiltrating the renal parenchyma, and wich is also for staging. 


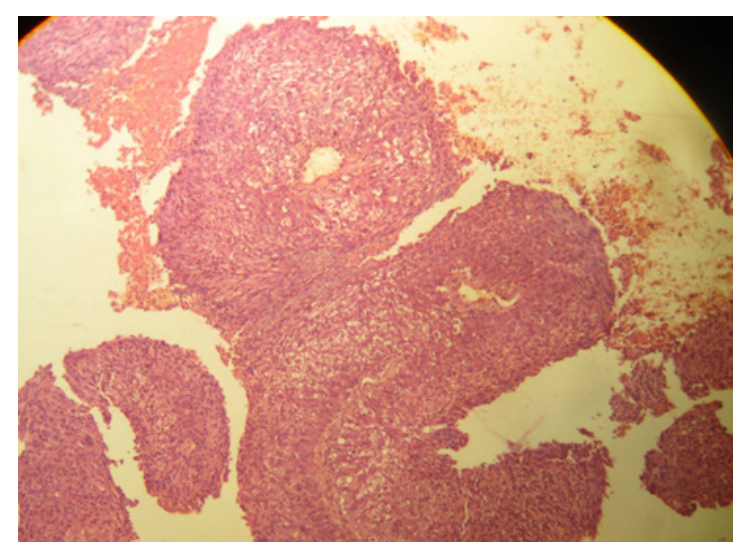

Figure $3 \mathrm{M} / \mathrm{E}, \mathrm{HE} * \mathrm{I} 00$ urothelial carcinoma infiltrating the pleura.

\section{Discussion}

\section{Tumors of upper tract (TVES)}

The TVES entities are rare and account for about $5 \%$ of urothelial carcinomas all reported worldwide. ${ }^{3}$ The incidence of TVES peak between 70 and 80 years with an average age of diagnosis is between $65-70$ years. $^{3}$ The young age of discovery in our case is explained by the youth of our population. They most commonly affect men with a sex ratio of 1.5 to 2, 8en Europe and the United State between the period of 1997 to $2010.3,4$ Our observation is the first case reported in Madagascar and no similar study is found in the Malagasy literature where the incidence of TVES unknown in our country.

TVES of risk factors are common to those of bladder tumors or smoking is widely incriminated with RR 2 or 3 compared to nonsmokers. ${ }^{4}$ The decoction of plants is the etiologic agent found in our observation and could be the source of our sporadic cases. A risk factor similar to those found in the Balkan nephropathy and Chinese herbs recognized and reported in the literature since $1950 .{ }^{3}$ The discovery of TVES is happy chance in 10 to $16 \%$ of cases depending on the series with the waning of abdominal imaging performed for another reason. ${ }^{5}$ A pleurisy operating in a context of an impaired general condition us discover renal tumor after scannographic etiologic. Our case is a circumstance of discovery rarely reported in the literature and demonstrates advanced or metastatic TVES. ${ }^{6}$ Other more specific functional signs are indicative of these tumors such as hematuria $(68-82 \%)$, pain $(20-30 \%)$ or lumbar mass $(10 \%) .^{3}$ According to the recommendation of the AFU and the UAE (grade C), the USSR (flexible ureterorenoscopy) allows both to make the diagnosis (biopsy, cytology in situ) and conservative treatment of TVES in a time.? Morphologically, the uro-scanner potentiated by furosemide injection is the reference imaging modality with a sensitivity and specificity of around $96 \%$ and $99 \%$ as against 50 to $60.5 \%$ for IVU. ${ }^{8}$ MRI can replace the uro-scanner but is not realized as first-line diagnosis or staging as if our observation. ${ }^{8}$

\section{Pleural metastasis of urothelial carcinoma}

If the bladder carcinomas are known to provide multiple forms of thoracic metastatic disease: solitary or multiple nodules, infiltrates segmental, or more rarely, Pancoast syndrome, acute respiratory distress syndrome, sarcoidosis pseudo-appearance, or excavations lung. ${ }^{9}$ Pleural metastatic location is very unusual and rarely indicative of the disease. Rare clinical cases are reported in the literature. ${ }^{10}$ Odier et al., ${ }^{9}$ reported a similar observation with unilateral pleural involvement, of pseudomésothéliomateux appearance. ${ }^{9}$ Post mortem studies suggest that pleural carcinomatosis lesions are secondary to lymphatic or blood-borne spread or mixed tumor emboli. These attacks carry an aspect of pleural thickening ensheathing scalloped tumor or associated with pleurisy. ${ }^{4,9}$ These radiological lesions pose a differential diagnosis problem with mesothelioma and other pleural metastatic affected (adenocarcinoma, squamous cell carcinoma, sarcoma, melanoma, lymphoma). ${ }^{2}$ The diagnosis of these disorders is based on immunohistochemical examination of a pleural biopsy and has a prognostic value, therapeutic and forensic importance for patients exposed to asbestos.

\section{Management of metastatic urothelial carcinoma}

The treatment of metastatic urothelial carcinoma is based on the instillation of topical agents adjuvants (BCG or mitomycin C), chemotherapy (MVAC: Methotrexate, Vinblastine, Cisplatin Adriamycinand) and/or external beam radiation therapy. ${ }^{10}$ These treatments are mainly based on the transposition of the management principles of bladder tumors. We decided, in our case, the BCG instillation Pastor by percutaneous nephrostomy and the tear- $\mathrm{X}$ in favor of heavy chemotherapy before the alteration of the general state of our patient and the absence of technical platform radiotherapy in our center.

\section{Conclusion}

This case illustrates a rare and fatal pleural metastasis of urothelial carcinoma of the upper tract manifested by atypical radiological appearance of pseudomésothéliome. Nevertheless, we consider that our choice of therapy is judiciable in a developing country with a fragile health system given the prognosis of metastatic urothelial carcinoma according to the EBA report 2014. ${ }^{11}$

\section{Acknowledgments}

None.

\section{Conflicts of interest}

Authors declare that there is no conflict of interest.

\section{References}

1. Azémara MD, Audouina M, Revauxa A, et al. Tumeur urothéliale primitive du haut appareil urinaire et seconde localisation ultérieure intravésicale. Progrès en urologie. 2009;19(9):583-589.

2. Huang CC, Attele A, Michael CW. Cytomorphologic features of metastatic urothelial carcinoma in serous effusions. Diagnostic Cytopathology. 2012;41(7):569-574.

3. Ouzzane A, Roupret M, Leon P, et al. Epidémiologie et facteurs de risque des tumeurs de la voie excrétrice urinaire supérieure: revue de la littérature pour le rapport annuel de l'AFU. Progrès en urologie. 2014;24(15):966976.

4. Bach AM, Zhang J. Atlas of Genitourinary Oncological Imaging. Atlas of Oncology Imaging, Springer Science+Business Media: New York, USA; 2013. 45-64 p.

5. Hurel S, Roupret M, Seisen T, et al. Influence of preoperative factors on the oncologic outcome for upper urinary tract urothelial carcinoma after radical nephroureterectomy. Word J Urol. 2014;33(3):335-341.

6. Raman JD, Shariat SF, Karakiewicz PI, et al. Does preoperative symptom classification impact prognosis in patients with clinically localized upper 
tract urothélial carcinoma managed by radical nephroureterectomy? Urol Oncol. 2011;29(6):716-723.

7. Roupret M, Babjuk M, Comperat E, et al. European guidelines on upper tract urothelial carcinoma: 2013 update. Eur Urol. 2013;63(6):1059-1071.

8. Puech P, Roupret M, Renard-Penna R, et al. Imagerie des tumeurs des voies excrétrices supérieures: état de l'art pour le rapport scientifique annuel de l'AFU. Progrès en urologie. 2014;24(15):987-999.

9. Odier L, Labussiere H, Bayle F, et al. Détresse respiratoire aiguë avec aspect radiologique pseudomésothéliomateux. Rev Mal Respir. 2008;25(9):11451147.
10. Audenet F, Roupret M, Houédé N, et al. Traitements non chirurgicaux des tumeurs de la voie excrétrice supérieure : état de l'art pour le rapport annuel de l'AFU. Progrès en urologie. 2014;24:1030-1040.

11. Colin P, Irani J, Drouin SJ, et al. Facteurs pronostiques des tumeurs de la voie excretrice supérieure et impact sur la survie: une revue systématique pour le rapport annuel de l'AFU. Progrès en urologie. 2014;24:1000-1010. 